\title{
Clube do Resgate: Um jogo digital baseado em localização para a conscientização contra o abandono de animais
}

\author{
Mateus Pinheiro (Líder), David Miranda, Izac Sidarta, Patrick Nobre, Espedito Roza \\ Instituto UFC Virtual \\ Universidade Federal do Ceará \\ Fortaleza, Ceará, Brasil \\ mateus@virtual.ufc.br, dmottamiranda@gmail.com, izacsidarta@gmail.com, patrick.nobre12@gmail.com, \\ espedito.mesquita@gmail.com
}

\section{RESUMO}

O abandono de animais é um problema comum no Brasil, principalmente em grandes centros urbanos. Além da preocupação com os animais, esta situação também se configura como uma problema de saúde pública. Após entrevistas com usuários observou-se que a mudança na realidade em que os animais desemparados vivem não aconteceria sem uma mudança na consciência da população. A falta de educação e empatia são apontadas como uns dos principais obstáculos no combate ao problema. Vários tipos de soluções ao problema apresentado já foram realizadas, porém apenas de forma pontual e paliativa. Para intervir no problema do abandono e adoção de animais, este artigo descreve a criação do Clube do Resgate, um jogo baseado em localização para dispositivos móveis com características de RolePlaying Game (RPG). A solução consiste em três pilares: Intervenções físicas, disponibilidade de informações e jogo. A partir disso, existem muitas oportunidades de expansões como eventos sazonais, feiras de adoção, campanhas de vacinação entre outras atividades relacionadas ao jogo tanto no meio digital como real.

\section{PALAVRAS-CHAVE}

Design de jogos, processo de design, jogos baseados em localização, abandono de animais, conscientização

\section{Introdução}

A situação de abandono é vivenciada atualmente por diversos animais em todo o Brasil. Essa realidade é um problema principalmente em grandes centros urbanos, onde esses animais são diariamente vítimas de acidentes de trânsito, envenenamentos, agressões físicas e doenças. O abandono de animais também é uma questão de saúde pública, visto que várias Permission to reproduce or distribute, in whole or in part, material extracted from this work, verbatim, adapted or remixed, as well as the creation or production from the content of such work, is granted without fee for non-commercial use, provided that the original work is properly credited.

IHC 2019 - Competição de Design, Outubro 21-25, 2019, Vitória, Brasil. In Anais Estendidos do XVIII Simpósio Brasileiro sobre Fatores Humanos em Sistemas Computacionais. Porto Alegre: SBC.

(C) 2019 by the author(s), in accordance with the terms of the Creative Commons Attribution-NonCommercial 4.0 International Public License (CC BY-NC 4.0). das doenças que afligem esses animais também possuem potencial de contágio em humanos, como por exemplo a hidrofobia (raiva) e leishmaniose (calazar) [5]. Sendo assim, vários veículos municipais atuam no combate ao problema, realizando campanhas de vacinação, castração, adoção e conscientização sobre a causa, além de trazer outras informações para a população.

Atualmente, o ato de abandonar animais domésticos na rua além de agravar o problema configura crime federal [4], mas mesmo tal medida não impede que essa prática ocorra por todo o território nacional. Este documento relata o processo de design de uma solução digital para os problemas supracitados.

\section{Metodologia}

O projeto foi desenvolvido seguindo o design centrado no usuário [9], dividindo-se quatro etapas que podem ser visualizadas no quadro 1.

O framework DECIDE [12] foi essencial durante o projeto para melhor organização e planejamento dos processos de avaliação, sendo utilizado tanto na fase de coleta de dados quanto na avaliação do protótipo produzido. Os objetivos da primeira fase foram: (1) entender a visão dos cidadãos sobre o problema, (2) entender a perspectiva de veterinários e pessoas envolvidas na causa, (3) conhecer tentativas já utilizadas de solução classificando-as por tipo e efetividade, (4) conhecer a legislação e o impacto ambiental do problema em questão. Um questionário online foi aplicado para entender a visão geral dos cidadãos sobre o problema, respondido por 510 pessoas de todas as regiões do Brasil. Devido à divulgação pela internet, percebeu-se um viés nas participações, onde as pessoas que se disponibilizaram a responder já tinham algum envolvimento com a causa. Em busca de opiniões mais diversas foram aplicadas entrevistas estruturadas com cinquenta participantes universitários. Por fim, foram executadas entrevistas semi-estruturadas aliadas a mapas de empatia com seis especialistas (entre veterinários e voluntários de Organizações não Governamentais - ONGs).

Os dados coletados foram triangulados a fim de identificar os perfis e desenvolver personas e requisitos [8] que guiaram as próximas fases. Os perfis identificados foram nomeados como: (1) pessoas engajadas e (2) pessoas pouco/não engajadas. O primeiro 
foi composto por pessoas que atuam na causa de forma próxima e constante (e.g.: voluntário em ações, compartilhamento e ajuda em campanha online). Já o segundo perfil é composto por pessoas que não costumam se envolver com a causa e pessoas que afirmam não gostar de animais e/ou são indiferentes ao tema.

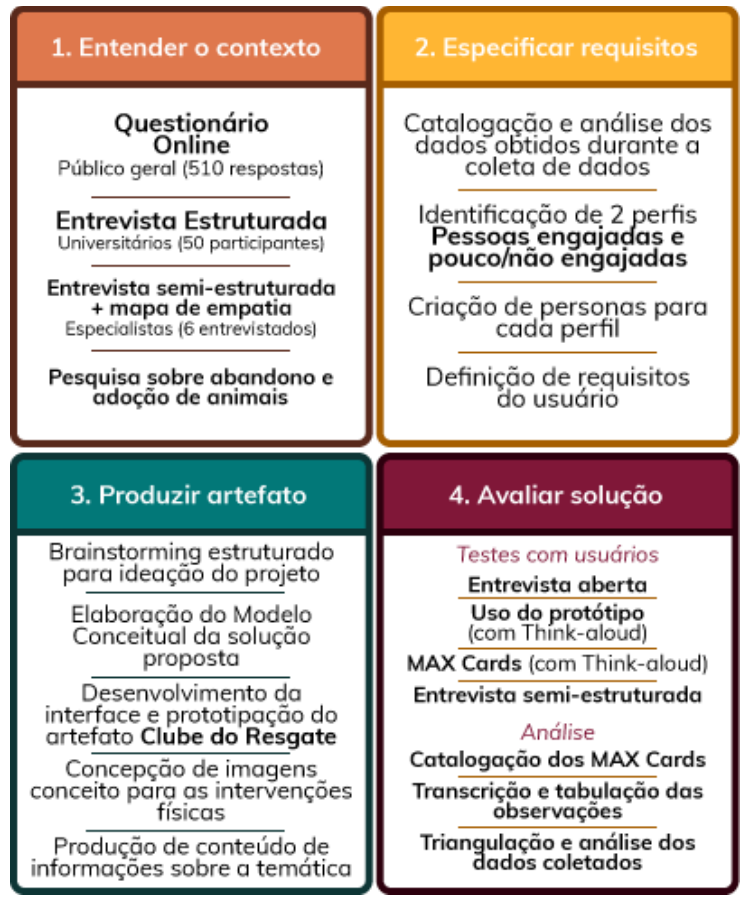

Quadro 1: Quatro fases da metodologia utilizada

Após a coleta de dados, realizou-se um brainstorming estruturado [2] direcionado através das personas desenvolvidas sobre os perfis identificados. A partir da ideia criada, ocorreu a elaboração de um modelo conceitual [1] da solução para que houvesse uma melhor compreensão e definição do projeto. Com isso, iniciou-se a fase de prototipação da solução com criação de moodboards e protótipos de baixa, média e alta fidelidade. Para desenvolver a mecânicas do jogo foi utilizado o framework Octalysis [7], que guia o processo através de uma série de elementos de devem ser contemplados.

$\mathrm{Na}$ avaliação, foram realizados testes com usuários utilizando um protótipo de navegação e um protótipo para testar a mecânica de batalha, em quatro momentos: (1) entrevista preliminar; (2) interação com o artefato; (3) aplicação da ferramenta de avaliação de experiência, MAX [6], e (4) entrevista semi-estruturada. A entrevista preliminar teve como objetivo identificar o perfil do participante. A interação foi guiada através de cenários de uso em que os usuários deveriam realizar tarefas. A seguir, foi realizado a aplicação do $M A X$ a fim de podermos avaliar a experiência do usuário. Por fim, aplicou-se uma entrevista para coletar

\footnotetext{
https:/g1.globo.com/sp/campinas-regiao/noticia/projeto-instala-comedourospara-caes-abandonados-nas-ruas-de-americana.ghtml

2 http://g1.globo.com/sc/santa-catarina/noticia/2016/06/projeto-instala-casinhasnas-ruas-para-animais-abandonados-em-lages-sc.html
}

informações relacionadas ao entendimento da proposta. Os testes contaram com a participação de dez usuários, entre homens e mulheres, divididos entre os perfis previamente observados. Em todas as participações de usuários nas fases de pesquisa foram realizados teste piloto e foram observados os fatores éticos.

\section{Justificativa}

Dados das entrevistas apontaram que a mudança na realidade em que os animais desemparados vivem não aconteceria sem uma mudança na consciência da população. A falta de educação e empatia são apontadas como uns dos principais obstáculos no combate ao problema. Ademais, vários tipos de abordagens ao problema apresentado já foram realizadas, porém apenas de forma pontual e paliativa. Ações como o Alimentacão ${ }^{1}$, construindo comedouros com canos PVC para os animais, abrigos em forma de casinhas para os animais em Santa Catarina ${ }^{2}$, esculturas de animais feitas de lixo ${ }^{3}$ e campanhas de adoção são exemplos já existentes, porém sem uma um forte laço entre várias dessas atividades como uma só em busca da conscientização da população. Foi observado também que boa parte da população não está ciente que abandonar animais configura crime federal e, portanto, muitos não acionam a polícia ao testemunharem tais atos.

Com base nisso, o desenvolvimento da solução foi direcionado para o viés de conscientização a respeito das questões supracitadas. A escolha de desenvolver um jogo se deu pelo seu potencial lúdico e estimulante, contribuindo para a transmissão de mensagens à população. Dado os perfis identificados na fase de pesquisa, a proposta visa incentivar a participação ativa dos simpatizantes com a causa animal e gerar consciência e empatia sobre o tema nos usuários indiferentes.

\section{Proposta}

O Clube do Resgate é um jogo baseado em localização [11] para dispositivos móveis com características de Role-playing game $(R P G)[10]$. A solução consiste em três pilares: Intervenções físicas, disponibilidade de informações e jogo.

\subsection{Intervenções Físicas}

As intervenções físicas se dão de duas maneiras: através das Mensagens físicas e dos Comedouros.

Os Comedouros consistem em máquinas alimentadoras autônomas, como na imagem 1, situadas em regiões com grande concentração de animais de rua. A máquina possui um sistema de detecção do nível de ração e água, fazendo a reposição quando for necessário. Possuirá também um sistema de segurança para que apenas a instituição responsável possa reabastecê-la, evitando assim que pessoas mal intencionadas possam adulterar a ração.

\footnotetext{
3 https://catracalivre.com.br/parceiros-catraca/causando/esculturas-de-saco-delixo-alertam-para-abandono-de-caes/
} 
Clube do Resgate: Um jogo digital baseado em localização para a conscientização contra o abandono

Devido sua automação, a ração só será liberada quando a tigela estiver vazia, evitando assim a proliferação de pragas urbanas e garantindo a qualidade do alimento. Além disso, não será necessária a reposição constante de alimento, bastando apenas preencher o refil da máquina periodicamente. Para aumentar o engajamento um sinal sonoro e luminoso será emitido quando a tigela de comida estiver vazia, convidado a população a apertar o botão e liberar comida. Após acionado pelo botão, o comedouro emite um reforço positivo sonoro. Caso ninguém interaja após um tempo pré-determinado, o dispositivo libera a ração automaticamente.

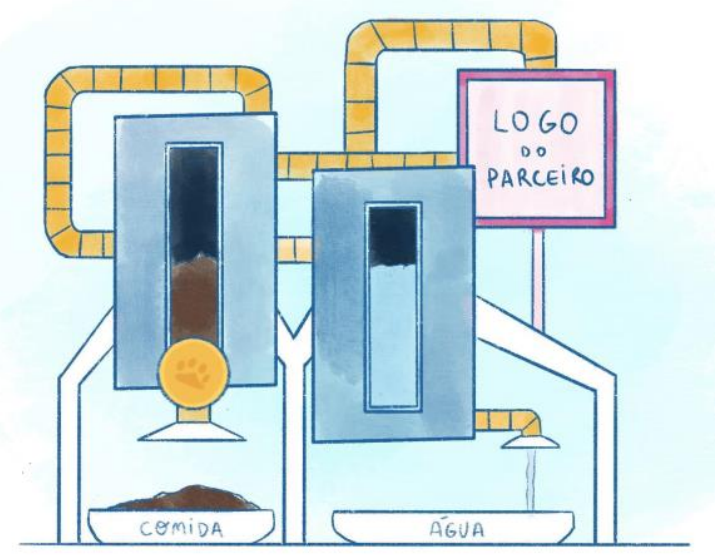

Imagem 1: Imagem conceito de um comedouro

Já as mensagens físicas consistem em manifestações artísticas espalhadas pela cidade com objetivo de conscientização acerca da causa animal, como pode ser visto na imagem 2. Mensagens físicas podem ser compostas por pinturas, cartazes ou esculturas. O potencial desta intervenção está na capacidade de atingir não apenas jogadores, mas também as demais pessoas que transitam no local. Alguns exemplos podem ser visualizados nos anexos.

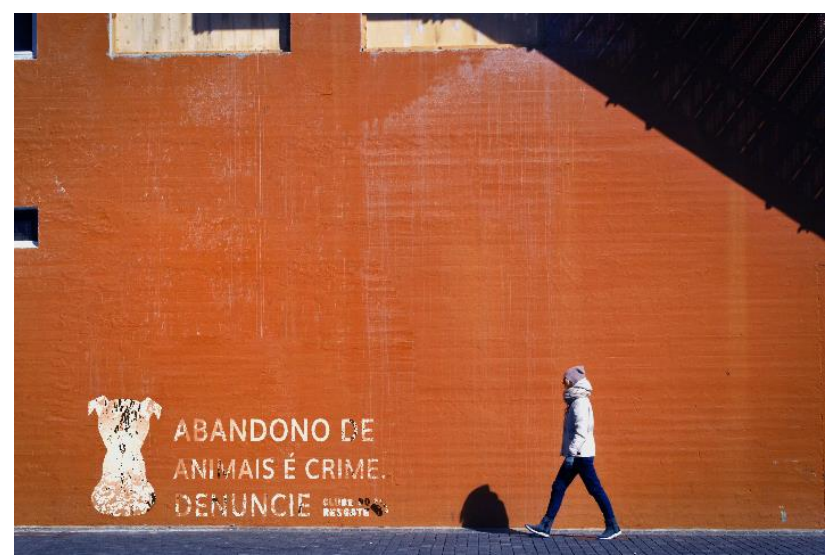

Imagem 2: Intervenção artística sobre o abandono de animais.
IHC 19, Julho, 2019, Vitória, Espírito Santo, Brasil

\subsection{Disponibilidade de informações}

Uma seção da aplicação móvel disponibiliza informações relevantes a respeito do universo animal, como cuidados básicos, contatos, informações sobre adoção consciente, resgate, castração, vacinação e curiosidades. O agrupamento dessas informações de forma prática e amigável facilita o engajamento de usuários que desejem ajudar a causa animal fora do ambiente do jogo. Além disso, a aplicação convida o usuário a consumir estes conteúdos de forma contextualizada através de mensagens durante a interação (e.g.: ao completar a ação de vacinar seus animais virtuais, o jogo convida o usuário a ler um pouco sobre vacinação de animais no mundo real). Dessa forma, os conceitos trabalhados no jogo ficam bem conectados com o mundo real, evitando que os usuários fiquem alienados.

\subsection{O jogo}

Os jogadores entrarão em um mundo de fantasia tendo como objetivo ajudar os animais abandonados. Nesse mundo fictício, os animais estão sofrendo com entidades chamadas "Sombras do Abandono", que se manifestam como sintomas da depressão animal [13]. Essas sombras aparecem por todo o mapa e sugam a vitalidade dos animais abandonados, deixando-os fracos e doentes. Para combater esse mal, o jogador contará com a ajuda de seu companheiro animal, uma criatura dotada de poderes mágicos que canalizam sentimentos positivos, para expurgar as sombras e ajudar os animais abandonados. O jogo oferece uma série de mecânicas que podem ser visualizadas no quadro 2 .

A batalha contra as sombras ocorre em turnos alternados entre o jogador e as sombras. O jogador seleciona uma de suas habilidades, escolhidas antes da batalha, para agir através de seu companheiro animal, em seguida a sombra age. As habilidades são metáforas à sentimentos positivos e gestos de cuidado (e.g.: raio de conforto, chuva de empatia), tirando a conotação violenta que o conceito de batalha carrega. Tanto os companheiros animais quanto as sombras possuem três atributos principais que servem de base para cálculos da batalha e também para a aquisição de novas habilidades: Poder (quantifica a eficácia das habilidades), Resistência (capacidade de resistir às habilidades do oponente) e Velocidade (capacidade de agir múltiplas vezes em um único movimento). O objetivo é expulsar a sombra, reduzindo sua energia a zero Caso o companheiro animal tenha sua energia reduzida a zero, ele ficará temporariamente incapacitado e não poderá batalhar por alguns minutos. Nesse caso, o jogador pode esperar o tempo de descanso do companheiro animal ou fazer o uso de itens consumíveis que recuperam a energia do animal de forma mais rápida para pode voltar a jogar logo. Após expurgar a sombra, um animal é libertado. 


\begin{tabular}{|l|l|}
\hline Elementos Octalysis & $\begin{array}{l}\text { Características do jogo } \\
\text { Clube do Resgate }\end{array}$ \\
\hline Meaning & Trama do jogo \\
$\begin{array}{l}\text { Enpowerment of } \\
\text { creativity }\end{array}$ & $\begin{array}{l}\text { Customização do companheiro } \\
\text { animal } \\
\text { Social Influence }\end{array}$ \\
Unpredictability & $\begin{array}{l}\text { Sistema de amigos } \\
\text { endomização de combate }\end{array}$ \\
Avoidance & $\begin{array}{l}\text { Fuga das batalhas } \\
\text { Scarcity }\end{array}$ \\
Ownership & $\begin{array}{l}\text { Sistema de mantimentos } \\
\text { Sistemas de auras e habilidades }\end{array}$ \\
Accomplishment & $\begin{array}{l}\text { Missões, aquisição de habilidades } \\
\text { e nivel do companheiro animal }\end{array}$ \\
\hline
\end{tabular}

Quadro 2: Tabela de mecânicas do jogo baseadas no framework Octalysis

Os animais resgatados vão para um abrigo virtual, onde o jogador pode ajudá-los na recuperação fornecendo água, alimento e medicamentos. Com a saúde completamente recuperada, o animal estará apto a ser adotado por famílias virtuais. Cada adoção é recompensada com pontos de gratidão que são usados para subir o nível do companheiro animal. A adoção e a reposição de mantimentos virtuais são feitas através de localizações específicas na cidade (intervenções físicas). A ideia é convidar o jogador a percorrer a cidade, experienciando o cotidiano dos animais de rua e conhecendo outros jogadores. É possível completar missões para obter recompensas como acessórios e auras. Auras incrementam os atributos do seu companheiro e adiciona uma animação no fundo do perfil. Os acessórios não incrementam os atributos, mas modificam a aparência do seu companheiro. Alguns exemplos de missões são: "Combata cinco sombras" ou "Consiga um lar para três animais resgatados".

\section{Cenário de uso}

Um usuário descobre o jogo Clube do Resgate a partir das intervenções na cidade: se depara com a pintura de um cãozinho no banco de uma praça com a frase "Todo mundo precisa de amor e carinho. E todos somos capazes de dar um pouquinho". Curioso, o usuário baixa o jogo no seu celular, cria seu companheiro animal virtual, personaliza-o e escolhe suas habilidades.

Com seu companheiro animal pronto, o usuário anda pela cidade real e encontra uma das sombras no mapa do jogo. Ele batalha com a sombra, resgatando o animal debilitado para seu abrigo onde cuida dele com seus mantimentos, a fim de deixá-lo pronto para adoção. A escassez de mantimentos, após usá-los para o animal resgatado, fará com que o usuário precise ir até comedouros e/ou mensagens físicas que são indicados no mapa. Chegando lá, este poderá conhecer outros jogadores que estão na área e a situação dos animais de rua da vizinhança e, dentro da aplicação, coletar mantimentos (ração, água e remédios). Nos mesmos locais, ele também pode encontrar famílias virtuais para adotar o animal recuperado. Através disso ganha pontos de gratidão para evoluir seu companheiro e continuar na luta contras as sombras e no resgate dos animais.

\section{Viabilidade}

Os custos do desenvolvimento da presente intervenção são divididas em duas modalidades: custos iniciais (CI) e custos de manutenção (CM). A aplicação móvel demanda CI e CM maiores que os demais elementos da intervenção. O comedouro possuirá um CI relativamente alto quando comparado as mensagens. As mensagens são os elementos com menores CI e CM.

Para o desenvolvimento do software seriam necessários $\mathrm{R} \$$ 20.000,00 reais, considerando custo de desenvolvimento máximo de $\mathrm{R} \$ 200,00$ por dia, totalizando $\mathrm{R} \$ 18.000,00$ e mais $\mathrm{R} \$ 2.000,00$ para eventuais gastos adicionais. Demais custos (CM) seriam de cerca R\$ 500,00 por mês com manutenção do programa. Para redução dos custos ao longo do tempo, adotaria-se serviços gratuitos de hospedagem de servidor. $\mathrm{O}$ uso de ferramentas gratuitas como engines e editores de imagens podem ser facilmente adotados. Para a questão de banco de dados e APIs (Application Programming Interface), há uma grande variedade de excelentes serviços gratuitos e em nuvem que podem auxiliar o desenvolvimento do projeto durante seus primeiros anos. Por exemplo, temos o Firebase, Heroku e Amazon Web Services).

As mensagens contam com manifestações artísticas das mais diversas naturezas. As alternativas de menor custo seriam as pinturas do tipo estêncil e Tape arts. Para pinturas do tipo estêncil seriam necessárias latas de tintas spray com custo médio de R\$ 15,00 por lata. Moldes de estêncil podem varias de $\mathrm{R} \$ 15,00$ a $\mathrm{R} \$$ 45,00, sendo necessários em média três moldes para cada arte. Moldes podem ser reutilizados várias vezes. Para a tape art utilizam-se fitas adesivas decorativas com custo médio de R \$ 5,00 a unidade, sendo necessárias cerca de seis unidades de fita para uma cobertura de cerca de um metro quadrado. Em resumo, pinturas estêncil iriam custar $\mathrm{R} \$ 90,00$ devido aos moldes reutilizáveis e três latas de tinta que totalizam $R \$ 45,00$. A manutenção anual da obra consistiria na repintura da obra resultando em $\mathrm{R} \$ 45,00$ por ano. Para a tape art, um conjunto de seis fitas decoradas resultam em um valor médio de $R \$ 30,00$ por obra. A manutenção da obra seria a reaplicação das fitas, anualmente, totalizando $\mathrm{R} \$ 30,00$ de $\mathrm{CM}$.

Os comedouros serão instalados com a ajuda de empresas parceiras. Além de patrocinar, a empresa também terá o papel fundamental de reabastecer a máquina com água e ração. Em contrapartida a empresa poderá dispor sua logo no comedouro, além de demonstrar sua preocupação com a questão socioambiental. O CI estimado do comedouro é de R\$714,78. A máquina tem comporte para aproximado cinquenta quilos de ração, que devem ser abastecido periodicamente. $\mathrm{O}$ custo de abastecimento com ração é de $\mathrm{R} \$ 160,00$ e rende quinhentas porções de cem gramas. Cachorros comem em média duzentos gramas diariamente, enquanto gatos comem até cem gramas. 
Clube do Resgate: Um jogo digital baseado em localização para a conscientização contra o abandono

Para a manutenção e expansão da intervenção, podem ser adicionados meios em que os usuários possam fazer doações e comprar itens exclusivos dentro do jogo. Além disso, produtos temáticos (e.g.: coleiras, tigelas de ração, pelúcias, posters) podem ser desenvolvidos para que o lucro seja revertido para as expansões. Para além das expansões, o dinheiro arrecadado também será destinado a doações para instituições de abrigo para animais em situação de desamparo.

Para ver os valores mais detalhadamente, acesse o link a seguir: http://bit.ly/TabelaDeCustos

\section{Conclusão}

Os resultados da avaliação do jogo com usuários por meio de entrevistas aliado ao MAX, revelaram informações muito satisfatórias a respeito da aplicação. Todos os participantes da avaliação apreciaram o aspecto visual e entenderam o objetivo do jogo. A maioria dos participantes acreditam que a aplicação possui grande potencial para ensinar e/ou conscientizar sobre a causa, fator decisivo para o êxito da aplicação. Essa mudança na mentalidade dos jogadores é o que irá colaborar para a mudança na realidade vivenciada por animais em estado de abandono, como mostram as entrevistas realizadas na etapa da coleta de dados.

Após a avaliação, foram feitos reparos no protótipo com base nos reportes dos participantes, dos quais podemos destacar a alteração no logo do jogo e cor de fundo da tela inicial que, segundo alguns dos entrevistados durante a avaliação, não possuía consistência com a temática do jogo. Outras alterações diversas foram feitas (e.g.: posição de botões, tipografia, cenários e personagens).

O projeto apresentado possui uma base sólida de mecânicas. A partir disso, existem muitas oportunidades de expansões como eventos sazonais, feiras de adoção, campanhas de vacinação entre outras atividades relacionadas ao jogo tanto no meio digital como real. Assim, aumentam-se as chances do jogo se manter interessante para os usuários aumentando seu impacto na sociedade.

\section{Links}

Protótipo: http://bit.ly/PrototipoClubeDoResgateFinal

Vídeo demo: https://youtu.be/WLF0p8PPA80

Anexos: http://bit.ly/AnexoClubeDoResgate

\section{REFERÊNCIAS}

[1] Barbosa, S., \& Silva, B. (2010). Interação humano-computador. Elsevier Brasil.

[2] Behr, A., Moro, E. L. D. S., \& Estabel, L. B. (2008). Gestão da biblioteca escolar: metodologias, enfoques e aplicação de ferramentas de gestão e serviços de biblioteca. Ciência da informação. Brasília. Vol. 37, n. 2 (maio/ago. 2008), p. 3242.

[3] Bland, D. (2012). Agile coaching tip-What is an empathy map? Available in http://www. bigvisible. com/2012/06/what-is-an-empathy-map.

[4] BRASIL. Decreto-Lei n. 2.848, de 7 de dezembro de 1940. Código Penal. Rio de Janeiro, 1940. Disponível em: <http://www.planalto.gov.br/ccivil_03/decretolei/del2848compilado.htm>. Acesso em: 07 jul. 2019
IHC 19, Julho, 2019, Vitória, Espírito Santo, Brasil

[5] BRASIL. Ministério da Saúde. Secretaria de Vigilância em Saúde. Departamento de Vigilância das Doenças Transmissíveis. Manual de vigilância, prevenção e controle de zoonoses: normas técnicas e operacionais. Brasília: Ministério da Saúde, 2016.

[6] Cavalcante ${ }^{1}$, E., Rivero ${ }^{1}$, L., \& Conte $^{1}$, T. (2015). MAX: A Method for Evaluating the Post-use User eXperience through Cards and a Board. In: 27th International Conference on Software Engineering and Knowledge Engineering (SEKE 2015), 2015, Pittsburgh. Proceedings of the 27th International Conference on Software Engineering and Knowledge Engineering (SEKE 2015), 2015. v. 1. p. 495-500.

[7] Chou, Y. K. (2016). Actionable gamification: Beyond points, badges, and leaderboards. Octalysis Media.

[8] Ferreira, B., Barbosa, S., \& Conte, T. (2018, October). Creating Personas focused on Representing Potential Requirements to Support the Design of Applications. In Proceedings of the 17th Brazilian Symposium on Human Factors in Computing Systems (p. 15). ACM.

[9] ISO 9241-210:2019. Norma Internacional; classificação. Disponível em <https://www.iso.org/standard/77520.html>. Acesso em 08 jul. 2019.

[10] JACKSON, S. GURPS: generic universal role-playing system: modulo básico. São Paulo: Devir, 1994.

[11] Lemos, A. (2010). Jogos móveis locativos: Cibercultura, espaço urbano e mídia locativa. Revista USP, (86), 54-65.

[12] Rogers, Y., Sharp, H., \& Preece, J. (2013). Design de Interação. Bookman Editora

[13] Segata, J. (2012). Os cães com depressão e os seus humanos de estimação. Anuário Antropológico, p. 177-204. 